\title{
The influence of initiator and macrocyclic ligand on unsaturation and molar mass of poly(propylene oxide)s prepared with various anionic system
}

\author{
Zbigniew Grobelny ${ }^{1} \cdot$ Marek Matlengiewicz $^{1}$ • \\ Justyna Jurek-Suliga ${ }^{2}$ - Sylwia Golba ${ }^{2}$. \\ Kinga Skrzeczyna ${ }^{1}$
}

Received: 27 January 2017/Revised: 21 April 2017/Accepted: 19 May 2017/

Published online: 1 June 2017

(C) The Author(s) 2017. This article is an open access publication

\begin{abstract}
Anionic polymerization of propylene oxide was carried out in the presence of two groups of potassium salts activated 18-crown-6 (18C6), e.g. alkoxide salts $\left(\mathrm{CH}_{3} \mathrm{OK}, i\right.$-PrOK, $t$ - $\left.\mathrm{BuOK}, \mathrm{CH}_{3} \mathrm{OCH}_{2} \mathrm{CH}\left(\mathrm{CH}_{3}\right) \mathrm{OK}, \mathrm{KCH}_{2} \mathrm{O}\right)$ and other salts $\left(\mathrm{CbK}, \mathrm{Ph}_{3} \mathrm{CK}, \mathrm{Ph}_{2} \mathrm{PK}, \mathrm{Ph}_{3} \mathrm{HBK}, \mathrm{KK}, \mathrm{KH}\right.$, and $\left.\left[\left(\mathrm{CH}_{3}\right)_{3} \mathrm{Si}\right]_{2} \mathrm{NK}\right)$ in $\mathrm{THF}$ at room temperature. Application of various initiating systems results in polyethers which are different in level and kind of unsaturation represented by allyloxy, cis- and trans-propenyloxy, as well as vinyloxy starting groups. In the presence of selected initiator, i.e. $t$ - $\mathrm{BuO}^{-} \mathrm{K}^{+}$unsaturation increases markedly by addition of $18 \mathrm{C} 6$ or C222. During the initiation step oxirane ring-opening and direct deprotonation of the monomer occur simultaneously involving in some cases also the ligand. All initiators opens oxirane ring in the $\beta$-position except $i$-PrOK, which opens it in the $\beta$ - and $\alpha$-position. The mechanisms of the reactions were discussed.
\end{abstract}

Keywords Anionic polymerization · Poly(propylene oxide) · ROP · Potassium salts · Unsaturation · Macrocyclic ligands

\section{Introduction}

Anionic ring-opening polymerization of propylene oxide (PO) is industrially used for the preparation of oligomeric homopolymers and copolymers with ethylene oxide (EO). They are mostly applied as nonionic amphiphilic surfactants or polyether polyols for synthesis of polyurethanes (PU) [1-8]. The most frequently

Zbigniew Grobelny

zbigniew.grobelny@us.edu.pl

1 Institute of Chemistry, University of Silesia, 40-007 Katowice, Poland

2 Institute of Materials Science, University of Silesia, 40-007 Katowice, Poland 
used initiating systems involve $\mathrm{KOH}$ (catalyst) and 1,2-propylene glycol, glycerol or pentaerythritol (starters). The processes are carried out in bulk at high temperatures (105-125 ${ }^{\circ} \mathrm{C}$ ) and pressures (0.3-0.5 MPa) [7-9]. However, high molar mass poly(propylene oxide)s cannot be prepared by anionic polymerization because of an extensive chain transfer reaction to the monomer leading to the formation of macromolecules with allyloxy starting groups $\mathbf{4}$ which can isomerize to cis-propylenoxy ones 5 (Scheme 1) [10-12].

This reaction produces after hydrolysis the monoolic fraction of macromolecules, which limits molar mass $\left(M_{\mathrm{n}}\right)$ of polyethers to 3000-6000 and is disadvantageous for PU fabrication [8]. It is impossible to avoid the side reaction of hydrogen abstraction from the monomer but it is possible to minimize its extend. This reaction can be depressed by several methods, i.e. application of counter-ions with larger ionic radii, such as $\mathrm{Rb}^{+}$or $\mathrm{Cs}^{+}[13,14]$. Other practical way is to develop the polymerization at lower temperatures $[8,13]$. This effect is based on the different activating energies of the propagation reaction and of the transfer reaction. Another way is high hydroxyl groups concentration. It is well known [8] that in the case of polyethers used for rigid PU foams, having a high concentration of $\mathrm{OH}$ groups, the resulting unsaturation is extremely low. Conversely, the polyethers for flexible PU foams, having a low concentration of terminal $\mathrm{OH}$ groups, have high unsaturation. Similar influence of hydroxyl groups on the transfer reaction was reported in several works [8, 15-19]. The explanation of this phenomenon is based on the strong affinity of the alkoxide for hydroxyl groups. Protons of hydroxyl groups are more acidic than protons of methyl groups in monomer. As a consequence, hydroxyl groups being much stronger ligands than PO are preferentially complexed giving complex 6 and PO is eliminated from the alkoxide-PO complex 2 on Scheme 2 [8], resulting in the deceleration of the chain transfer to the monomer.

By the simple addition of crown ether complexing potassium cation, one can obtain a polyether polyol in a shorter time (around two to three times shorter) than for normal anionic PO polymerization without ligands [8]. Moreover, in 2007 Penczek et al. [20] reported in review paper concerning ring-opening polymerization of heterocyclic monomers that the side transfer reaction in propylene oxide polymerization can be depressed to the same extent by counterion complexation

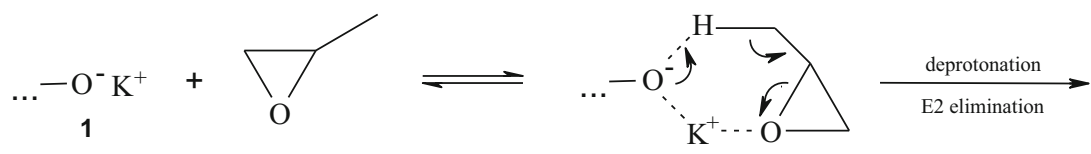

2
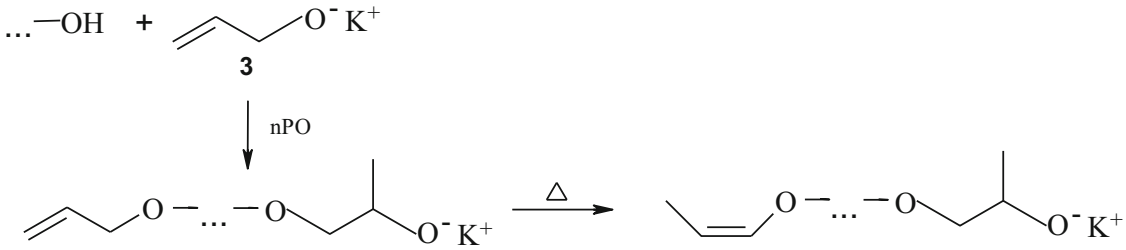

4

5

Scheme 1 Mechanism of the chain transfer reaction to the monomer in PO polymerization 


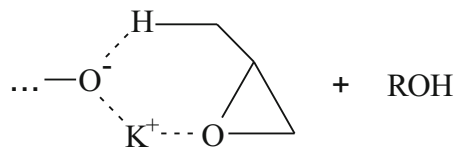

2

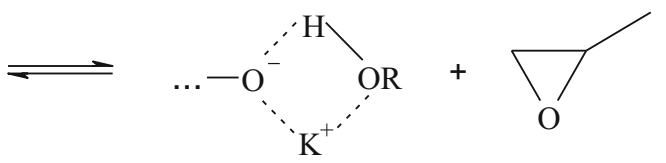

6

Scheme 2 Decomposition of the alkoxide-PO complex under influence of an alcohol and formation of more stable alkoxide-ROH complex

with crown ethers. However, the results presented in several works [8, 10, 21-23] revealed that this effect was observed in the systems containing compounds with $\mathrm{OH}$ groups. Addition of 18-crown-6 (18C6) to the systems containing alcohol causes further depression of chain transfer to the monomer resulting in distinct decreasing of unsaturation and increasing of $M_{\mathrm{n}}$ [8, 22]. For example, using a mixture of potassium 1-methoxy-2-propoxide/1-methoxy-2-propanol (1/3), $M_{\mathrm{n}}$ of polymers increases even to 12,400 at $[18 \mathrm{C} 6] /\left[\mathrm{K}^{+}\right]=1.5 / 1$ [21]. The minimum unsaturation of the polyether triols was found in the polymerization initiated with monopotassium salt of glycerin while using coronand 18C6 or cryptand C222, which appeared to be better ligands than dibenzo-18C6 or poly(ethylene glycol)s [21]. An explanation of this effect given by Ionescu [8] is the acceleration of propagation and the deceleration of the chain transfer to the monomer. The author proposed that using a strong complexing agent for $\mathrm{K}^{+}$, PO being a soft ligand is eliminated from the complex and thus chain transfer is inhibited (Scheme 3).

In the previous paper [23] we studied the influence of macrocyclic ligands and water on $\mathrm{PO}$ polymerization initiated with anhydrous $\mathrm{KOH}$. The lowest unsaturation and molar mass had polymer prepared by use of $\mathrm{KOH} / \mathrm{H}_{2} \mathrm{O} / 18 \mathrm{C} 6(1 / 1 / 1)$ initiating system. In this work, we reported new results concerning the effect of the kind of initiator and macrocyclic ligand on unsaturation of PPOs obtained by the use of several potassium salts without addition of hydroxylic compounds (Table 1). Mechanism of initiation of the polymerization were also studied and discussed. ${ }^{13} \mathrm{C}$ NMR, MALDI-TOF and SEC techniques were applied for characterization of the polymers.

\section{Experimental part}

\section{Materials}

Propylene oxide (Aldrich) was dried over $\mathrm{CaH}_{2}$ and finally distilled at $307 \mathrm{~K}$ $\left(34{ }^{\circ} \mathrm{C}\right.$ ). Anhydrous tetrahydrofuran (THF) (Across Organics) was kept over $\mathrm{CaH}_{2}$

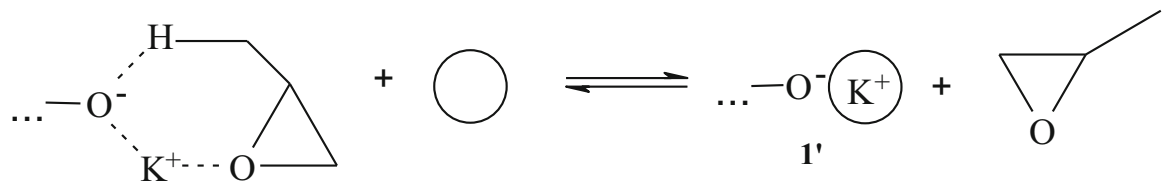

Scheme 3 Decomposition of alkoxide-PO complex in the presence of macrocyclic ligand 
Table 1 List of initiators utilized as initiators in the present study

\begin{tabular}{|c|c|c|c|c|c|}
\hline \multirow{7}{*}{ Alkoxides } & (1) & $\mathrm{CH}_{3} \mathrm{O}^{-} \mathrm{K}^{+}$ & \multirow{7}{*}{ Other salts } & (6) & $\mathrm{Ph}_{3} \mathrm{C} \mathrm{K}^{+}$ \\
\hline & (2) & i-PrO- $\mathrm{K}^{+}$ & & (7) & $\mathrm{Ph}_{2} \mathrm{P}^{-} \mathrm{K}^{+}$ \\
\hline & \multirow[b]{2}{*}{ (4) } & $\mathrm{CH}_{3} \mathrm{OCH}_{2} \mathrm{CH}\left(\mathrm{CH}_{3}\right) \mathrm{O}^{-} \mathrm{K}^{+}$ & & (8) & $\begin{array}{l}\mathrm{Cb}-\mathrm{K}^{+} \text {(a) } \\
\text { (a) } \mathrm{Cb} \text { - carbazolyl group }\end{array}$ \\
\hline & & $\mathrm{t}-\mathrm{BuO}^{-} \mathrm{K}^{+}$ & & (9) & $\mathrm{Ph}_{3} \mathrm{HB} \mathbb{K}^{+}$ \\
\hline & (5) & (K) $\mathrm{CH}_{2} \mathrm{O}^{-}$ & & (10) & {$\left[\left(\mathrm{CH}_{3}\right)_{3} \mathrm{Si}\right]_{2} \mathrm{~N} \mathrm{~K}^{+}$} \\
\hline & & & & (11) & $\mathrm{K}^{-} \mathrm{K}^{-}$ \\
\hline & & & & (12) & $\mathrm{K}^{-} \mathrm{H}^{-}$ \\
\hline & & & & (13) & K OH anhyd [23] \\
\hline
\end{tabular}

and distilled at $339 \mathrm{~K}\left(66^{\circ} \mathrm{C}\right)$. A $35 \mathrm{wt} \%$ dispersion of potassium hydride $(\mathrm{KH})$ in mineral oil (Aldrich) was mixed with $n$-pentane in a dry argon atmosphere and then decanted. That procedure was repeated three times followed by a threefold washing with dry tetrahydrofuran. Then, the solvent was evaporated in vacuum. The $\mathrm{KH}$ present was determined by a standard gas law calculation of the hydrogen liberated after treating with 2-butanol $\left(1.0 \mathrm{H}_{2}=1.0 \mathrm{KH}\right)$ [23]. The resulting solution was titrated to a phenolphthalein end point. Very little excess $(<1 \%)$ of total base over hydride base (from gas evolution) indicated small hydrolysis of the original $\mathrm{KH}$ sample. Coronand 18C6 (1,4,7,10,13,16-hexaoxacyclooctadecane) (Merck) and cryptand C222 (4,7,13,16,21,24-hexaoxa-1,10-diazabicyclo[8,8,8]hexacosane) (Merck) were used for synthesis without purification. Anhydrous methanol (Aldrich) and 2-hydroxymethyl-18-crown-6 (18C6-methanol) (Aldrich) were used for synthesis without purification. Other reagents, i.e. $i$-propanol, propylene glycol methyl ether, carbazole, triphenylmethane, potassium $t$-butoxide (1.0 M solution in THF), potassium bis(trimethylsilyl)amide, potassium triphenylborohydride $(0.5 \mathrm{M}$ solution in THF) and potassium diphenylphosphide (0.5 M solution in THF) all from (Aldrich) were also used without purification (Table 1).

\section{Propylene oxide polymerization}

All syntheses were performed at $20{ }^{\circ} \mathrm{C}$ in a $50 \mathrm{~cm}^{3}$ reactor equipped with a magnetic stirrer and a Teflon valve enabling substrates delivery and sampling under argon atmosphere. Potassium methoxide was obtained in the reaction of potassium hydride with methanol dissolved in tetrahydrofuran containing 18C6. The initial 
concentration of the monomer was equal to $2.0 \mathrm{~mol} / \mathrm{dm}^{3}$ and the initial amount of potassium methoxide was $0.70 \mathrm{~g} / \mathrm{dm}^{3}\left(0.1 \mathrm{~mol} / \mathrm{dm}^{3}\right)$. Potassium hydride $(0.08 \mathrm{~g}$, $2.0 \mathrm{mmol}), 18 \mathrm{C} 6(0.53 \mathrm{~g}, 2.0 \mathrm{mmol})$ and tetrahydrofuran $\left(17.2 \mathrm{~cm}^{3}\right)$ were introduced into the reactor and then methanol $\left(0.08 \mathrm{~cm}^{3}, 2.0 \mathrm{mmol}\right)$ was added by use of microsyringe, the reaction mixture was stirred during $2 \mathrm{~h}$ until all hydrogen $\left(44.7 \mathrm{~cm}^{3}\right)$ was evolved. It resulted in a fine dispersion of anhydrous potassium methoxide in the ether medium. Other salts, i.e. potassium $i$-propoxide, potassium propylene glycoxide methyl ether, carbazylpotassium and triphenylmethylpotassium [24] were synthesized the in similar way. Potassium potasside was prepared by dissolution of metallic potassium in THF containing 18C6 [25, 26]. All the systems were used as the initiators when propylene oxide $\left(2.8 \mathrm{~cm}^{3}, 2.3 \mathrm{~g}, 40 \mathrm{mmol}\right)$ was introduced into the reactor. The reaction mixture was then stirred for about 2 weeks. After complete conversion of the monomer (99\%) methyl iodide was added to transform alkoxide active centers into the methoxy end groups. After the potassium iodide precipitate had been separated, the solvent was evaporated at $20{ }^{\circ} \mathrm{C}$ yielding a viscous liquid polymer. The concentration of monomer during the polymerizations was monitored by the 1,4-dioxane method [27]. The yields of the reactions were 95-97\%.

\section{Preparation of pentaethylene glycol methyl vinyl ether (8)}

$\mathrm{KH}(1.0 \mathrm{~g}, 25 \mathrm{mmol})$ and THF $\left(100 \mathrm{~cm}^{3}\right)$ were introduced into the reactor. Then, diethylene glycol methyl ether $(3.0 \mathrm{~g}, 25 \mathrm{mmol})$ was added dropwise by microsyringe. The course of the reaction was monitored by measuring the amount of hydrogen liberated. After $2 \mathrm{~h}$ of stirring potassium diethylene glycoxide methyl ether in THF was prepared (solution 1). In separate experiment potassium ethylene glycoxide vinyl ether was synthesized in the reaction of $\mathrm{KH}(1.0 \mathrm{~g}, 25 \mathrm{mmol})$ in THF $\left(100 \mathrm{~cm}^{3}\right)$ with ethylene glycol vinyl ether $(2.2 \mathrm{~g}, 25 \mathrm{mmol})$ in the same manner. Then, 2-bromoethyl ether $(5.8 \mathrm{~g}, 25 \mathrm{mmol})$ was added to the reactor. After $5 \mathrm{~h}$ of stirring, solution 1 was introduced to the system. After another $2 \mathrm{~h}$ of stirring, the potassium bromide precipitate was separated by decantation. The product present in the solution was distilled in a Kugelrohr apparatus; the fraction boiling at $120{ }^{\circ} \mathrm{C}, 0.16$ mbar, consisted of pentaethylene glycol methyl vinyl ether. ${ }^{13} \mathrm{C}$ NMR (acetone- $\left.d_{6}\right): \delta 151.7(\mathrm{OCH}=) ; 86.5\left(\mathrm{CH}_{2}=\right) ; 67.1-71.0\left(\mathrm{OCH}_{2}, 6\right.$ signals); 58.9 $\left(\mathrm{CH}_{3}\right)$. MS: $m / e$ (rel intens) 219 (M-59, 0.1); 201 (0.2); 175(0.5); 147(0.5); 133(9); 117(7); 103(20); 87(18); 73(28); 59(100); 45(96); 43(45).

\section{Measurements}

$100 \mathrm{MHz}{ }^{13} \mathrm{C}$ NMR spectra were recorded in $\mathrm{CDCl}_{3}$ at $25{ }^{\circ} \mathrm{C}$ on a Bruker Avance 400 pulsed spectrometer equipped with $5 \mathrm{~mm}$ broad-band probe and applying Waltz 16 decoupling sequence. Chemical shifts were referenced to tetramethylsilane serving as an internal standard. To obtain a good spectrum of the polymer main chain exhibiting its microstructural details about 3000 scans were sufficient but to observe the signals of the polymer chain terminal groups more than 10,000 scans were necessary. Molar masses and dispersities of polymers were obtained by means 
of size exclusion chromatography (SEC) on a Shimadzu Prominance UFLC instrument at $40{ }^{\circ} \mathrm{C}$ on a Shodex $300 \mathrm{~mm} \times 8 \mathrm{~mm}$ OHpac column using THF as a solvent. Poly(propylene glycol)s were used as calibration standards. MALDI-TOF spectra were recorded on a Shimadzu AXIMA Performance instrument. Dithranol was used as a matrix. GS-MS analysis was run on a $30 \mathrm{~m}$ long DB1701 fused silica capillary column, using a Varian 3300 gas chromatograph equipped with a Finnigan MAT 800 AT ion trap detector. The methylated product (8) was identified by comparing its mass spectra and retention times with that of authentic compound. Diethylene glycol dimethyl ether was used as the internal standard for the yield measurements.

\section{Results and discussion}

\section{Influence of the kind of initiator on PPO unsaturation}

Propylene oxide polymerization was carried out at initial concentration of the monomer equal to $2.0 \mathrm{~mol} / \mathrm{dm}^{3}$ and initial concentration of the initiator and ligand equal to $0.1 \mathrm{~mol} / \mathrm{dm}^{3}$. Several salts activated $18 \mathrm{C} 6$ were used for initiation, such as potassium methoxide, potassium 18C6-methoxide, potassium $i$-propoxide, potassium $t$-butoxide, potassium propylene glycoxide methyl ether, triphenylmethylpotassium, carbazylpotassium, potassium triphenylborohydride, potassium diphenylphosphide, potassium hydride, potassium potasside and potassium bis(trimethylsilyl)amide. The effect of the kind of initiating polyreaction system on the level and kind of PPOs unsaturation was studied and discussed. Polymers were characterized by ${ }^{13} \mathrm{C}$ NMR for unsaturation and were subjected to size exclusion chromatography (SEC) for average molar mass $\left(M_{\mathrm{n}}\right)$ and dispersity $\left(M_{\mathrm{w}} /\right.$ $M_{\mathrm{n}}$ ) estimation. GC-MS and MALDI-TOF were also used as supported techniques for the study. The amounts of unsaturated starting groups in polymers were estimated in mol\% of all starting groups by measuring ${ }^{13} \mathrm{C}$ NMR signals intensities of appropriate carbon atoms. Figures 1 and 2 present both the amounts and kind of unsaturated starting groups in polymers obtained. They depend on the kind of initiator used-Fig. 1 shows results obtained in the presence of alkoxyl salts, while Fig. 2 shows results obtained in the presence of other salts.

Active anionic centers in initiators molecules and polymers growing chains have characteristic basicity $(b)$ and nucleophilicity $(n)$. Basicity is responsible for deprotonation of the monomer, whereas nucleophilicity for its ring opening. Hence, the value of $b / n$ ratio of initiator can be estimated from unsaturation level in the final polymeric substance. In all studied polymerisation, the basicity/nucleophilicity ( $b$ / $n$ ) ratio of alkoxide anion in growing chain end is obviously the same. As propagating species are the same for all chains, the results seem to indicate that the differences come from side reactions occurring only at the beginning (except the known transfer to monomer occurring during polymerisation). $B / n$ ratio of initiator 3 is very similar to that of growing chain end. Thus, the latter should be capable of undergoing transfer reaction with the monomer resulting in the polymer unsaturation. However, $b / n$ ratios of initiators $4,5,9,10,12$ and 13 are markedly greater 


\section{Kind of of unsaturated starting groups for macromolecules obtained with alkoxides}

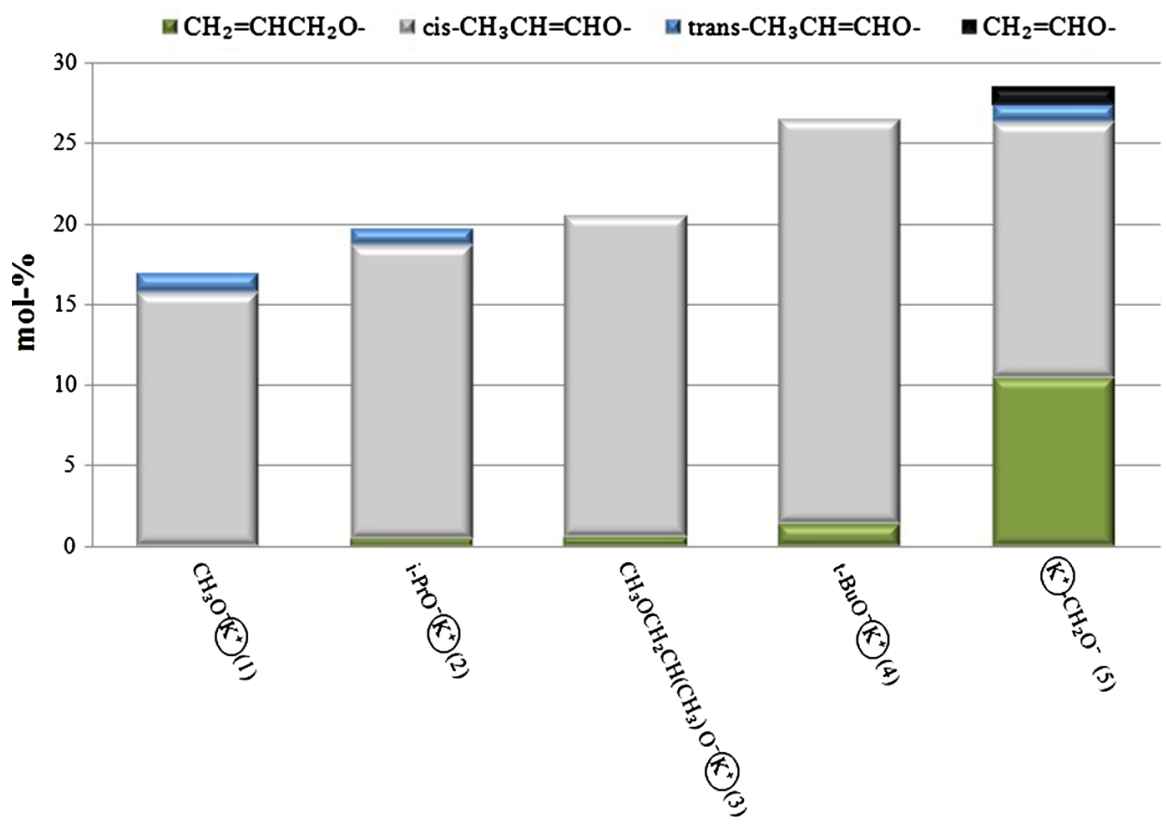

Fig. 1 Unsaturation level and kinds of unsaturated starting groups present in PPOs obtained with potassium alkoxyl salts activated $18 \mathrm{C} 6$

than that of the growing chain end. They differ from each other due to their different structure and influence on increase of polymer unsaturation. In the case of other initiators unsaturation of polymers is lower due to the fact that their $b / n$ ratios are lower than that of growing chain end ( 1 and 6). $B / n$ ratios of 2,7 and 8 are near to $b /$ $n$ of 3 . Thus, the polymers have unsaturation in wide range, that is, from $10.1 \mathrm{~mol} \%$ for $6-86.6 \mathrm{~mol} \%$ for 13 [23]. Similar effect was observed earlier by Kricheldorf et al. [28] in the polymerization of $\beta$-butyrolactone initiated with potassium salts of alcohols, phenols, carboxylic acids or amino acids, some of them being activated dibenzo-18C6. The high yield of trans-crotonate groups resulting from polymerization initiated with potassium $t$-butoxide or potassium 4-chlorothiophenoxide proves that direct deprotonation of the monomer by initiator does occur. Signals of initiators were not found in ${ }^{1} \mathrm{H}$ NMR spectra of the polymers obtained. It means that these initiators react exclusively as nonnucleophilic bases. Of particular interest is the formation of crotonate groups on addition of potassium benzoate (nucleophilic base). In this case $b / n$ ratios of initiator and growing chain end are the same and chain transfer to the monomer takes place. The only experiments which did not yield crotonate groups were the polymerization initiated with potassium benzylxanthogenate or potassium $N$ - $t$-butoxycarbonyl- $L$-alanine in bulk.

In the polymers obtained in the present work we observed four kinds of unsaturated starting groups, namely allyloxy, cis-propenyloxy, trans-propenyloxy 


\section{Kind of of unsaturated starting groups for macromolecules obtained with other salts}

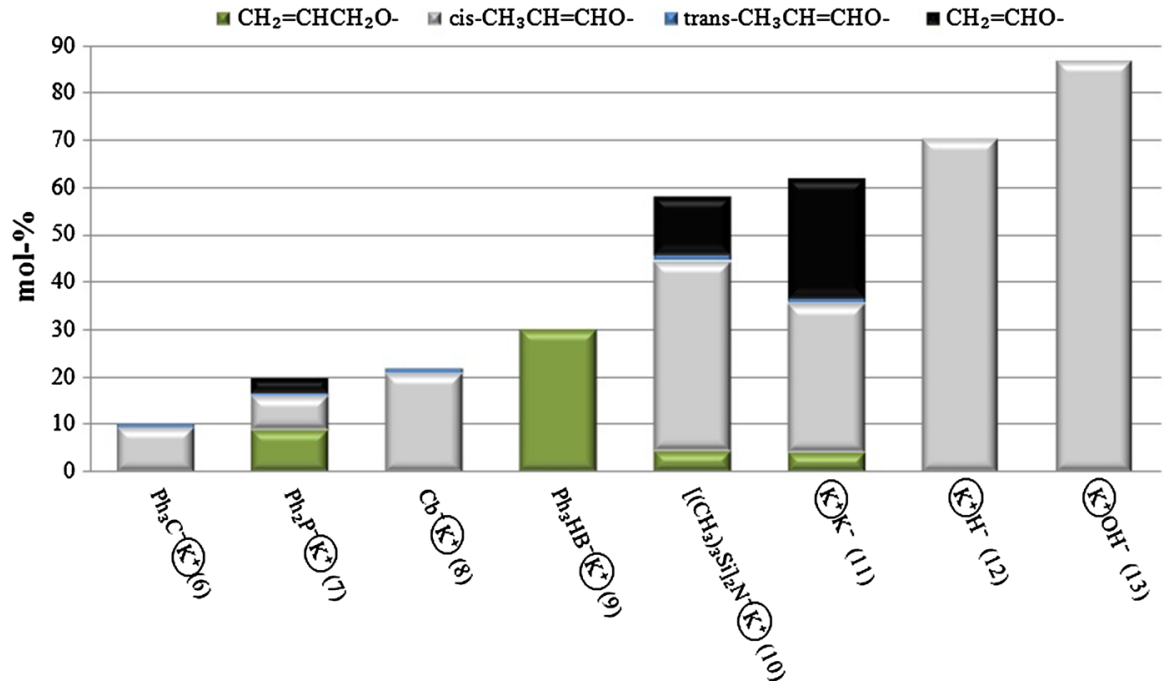

Fig. 2 Unsaturation level and kinds of unsaturated starting groups present in PPOs obtained with different other potassium salts activated $18 \mathrm{C} 6$, Cb denotes carbazolyl group, for $\mathrm{K}^{+} \mathrm{OH}^{-}$data from Ref. [23]

and unexpectedly, in some polymers also vinyloxy ones. Their level depended on the kind of initiator used. Allyloxy groups occured exclusively in polymer 9, whereas cis-propenyloxy ones are present in 6,12 and 13. In some polymers cispropenyloxy groups were accompanied with trans-propenyloxy ones, i.e. in 1 and 8. In four cases all kinds of mentioned unsaturated groups were accompanied with vinyloxy ones $(5,7,10$ and 11$)$. The most representative ${ }^{13} \mathrm{C}$ NMR spectrum of such kind of polymer (10) is depicted in Fig. 3. The unsaturated starting groups involve allyloxy $\underline{\mathrm{CH}}_{2}=\mathrm{CHCH}_{2} \mathrm{O}-(116.41$ and $134.63 \mathrm{ppm}$, respectively), cis-propenyloxy $\mathrm{CH}_{3} \mathrm{CH}=\mathrm{CHO}-\left(100.37\right.$ and $145.74 \mathrm{ppm}$, respectively), trans-propenyloxy $\mathrm{CH}_{3-}$ $\underline{\mathrm{CH}}=\underline{\mathrm{C}} \mathrm{HO}-\left(98.20\right.$ and $146.54 \mathrm{ppm}$, respectively), and vinyloxy ones $\mathrm{CH}_{2}=\underline{\mathrm{CHO}}-$ (86.91 and $151.32 \mathrm{ppm}$, respectively). In the saturated region of ${ }^{13} \mathrm{C} \mathrm{NMR}$ spectrum (not shown in Fig. 3) signal of methyl starting groups derived from the initiator (10), $\left[\left(\mathrm{CH}_{3}\right)_{3} \mathrm{Si}\right]_{2} \mathrm{~N}^{-} \mathrm{K}^{+}$, is detected at $1.32 \mathrm{ppm}$.

The spectrum reveals also the presence of hydroxyl end groups via its methine carbon signal $\left[-\underline{\mathrm{CH}}\left(\mathrm{CH}_{3}\right) \mathrm{OH}\right.$ at about $\left.\left.65.6 \mathrm{ppm}\right)\right]$ and methoxy end groups $\left(-\mathrm{OCH}_{3}\right.$ at about $56.6 \mathrm{ppm})$.

Different initial level of allyloxy groups in polymers indicate that they form not only in chain transfer reaction to the monomer but also by deprotonation of monomer with initiator (reactions 1 and 2 on Scheme 4).

The ability of crowned active ion pair $\mathbf{1}^{\prime}$ in growing chain to deprotonation of monomer indicates that explanation of chain transfer inhibition by complexation of counterion given by Ionescu [8] is contrary to our results. 


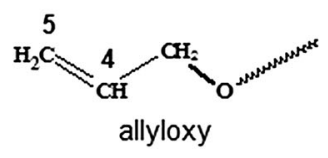

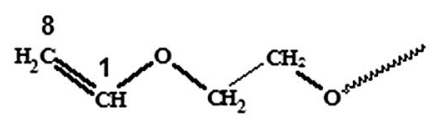

vinyloxy<smiles>C/C=C\OCC</smiles><smiles>CC=COC</smiles>

trans-propenyloxy

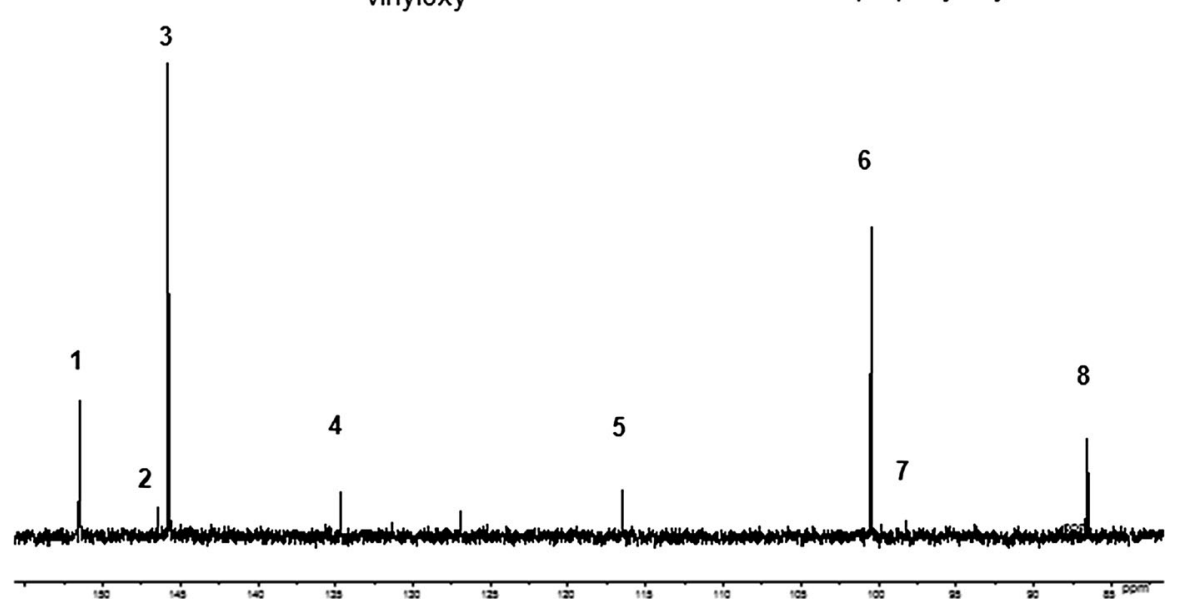

Fig. 3 Unsaturated region in ${ }^{13} \mathrm{C}$ NMR spectrum of polymer 10

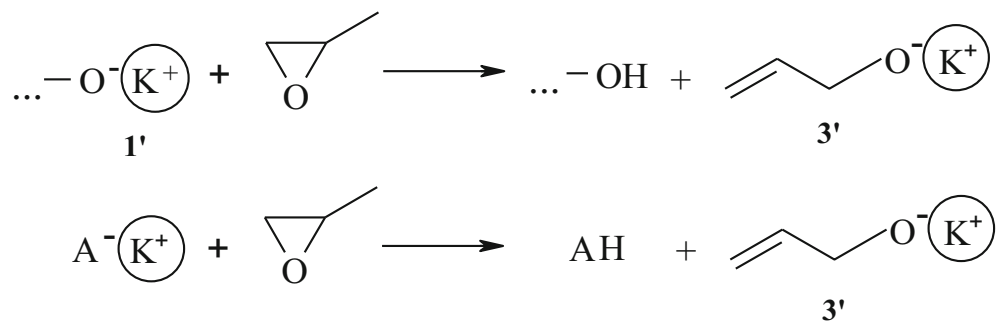

Scheme 4 Deprotonation of monomer by active chain end and initiator in the polymerization initiated with potassium salts activated ligand

Cis- and trans-propenyloxy groups are generated by isomerization of allyloxy ones. We suggested that formation of cis-propenyloxy groups can occur not only via intermolecular reaction (Scheme 1) but also in intramolecular reaction of initiator with macromolecules $\mathbf{4}^{\prime}$ (Scheme 5).

However, the source of vinyloxy starting groups formed in some systems is quite different. We assumed that they were created in the reaction of initiator with the ligand. Mechanism of this reaction will be discussed in "Mechanistic aspects of initiation of PO polymerization". 

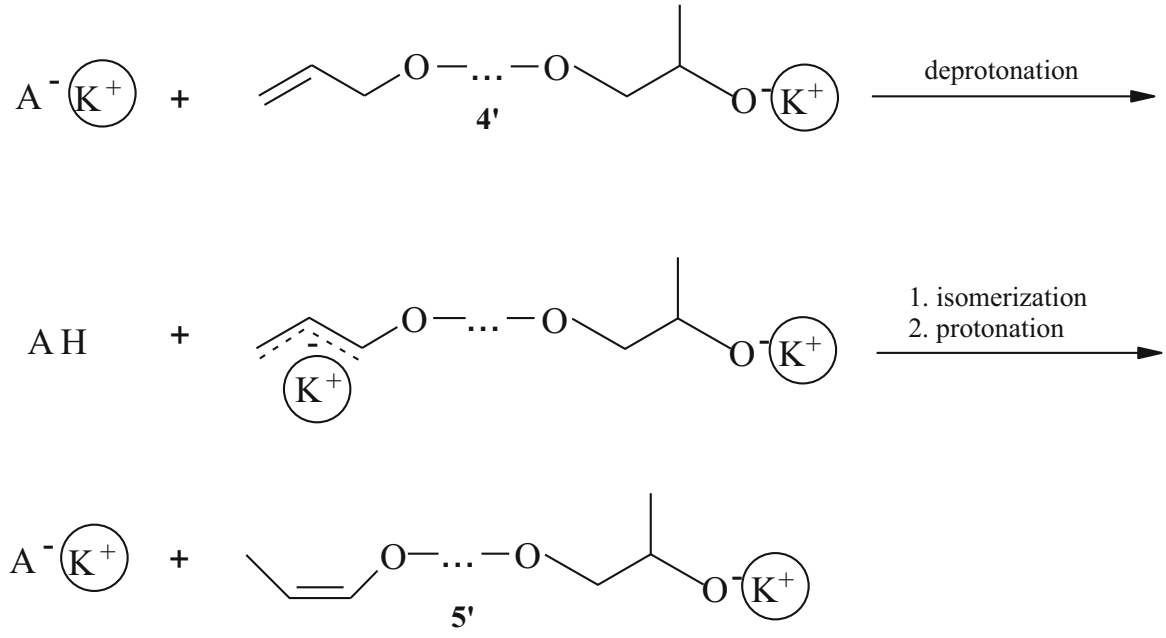

Scheme 5 Isomerization of allyloxy groups to $c i s$-propenyloxy ones mediated with initiator

In most cases, the studied polymerizations occurred in homogenous systems (except 1, 2, 12 and 13). Average molar masses of polymers were determined by SEC using poly(propylene glycol) standards. They were in the range of 1600-2900. These values are lower in comparison to $M_{\mathrm{n}}=4400$ obtained for PPO synthesized in the similar condition with $\mathrm{KOH}$ as initiator (13) [23]. Dispersities of polymers are relatively low (1.05-1.3), which indicates rapid counterion exchange reaction. However, $M_{\mathrm{n}}$ of all polymers are higher than theoretical molar masses calculated from Eq. (1).

$$
M_{\text {calc }}=\left([\mathrm{PO}]_{0} /[I]_{0}\right) M_{\mathrm{PO}} \approx 1160
$$

Transfer reaction causes decrease of $M_{\mathrm{n}}$. It indicates that some amount of potassium salts is inactive even if they are soluble in THF, probably due to the formation of ionic aggregates.

\section{Effect of macrocyclic ligands on the PPO unsaturation}

The influence of the presence and kind of macrocyclic ligand on unsaturation and molar masses of PPOs was determined previously by us for polymerization initiated with anhydrous $\mathrm{KOH}$ [23]. Unsaturation is very high in the systems without ligands and does not depend on initial monomer concentration. At low initial monomer concentration, i.e. $2.0 \mathrm{~mol} / \mathrm{dm}^{3}$ unsaturation increases in the presence of ligands, i.e. $18 \mathrm{C} 6$ and $\mathrm{C} 222$.

In this work, potassium $t$-butoxide nonactivated and activated macrocyclic ligand was selected for the study. Polymerizations were carried out at various initial monomer concentrations, that is 2.0 (gives polymers abbreviated as $4 \mathrm{a}-4 \mathrm{c}$ in Fig. 4), 5.0 (results in polymers denoted as $4 \mathrm{a}^{\prime}-4 \mathrm{c}^{\prime}$ ) and $10.0 \mathrm{~mol} / \mathrm{dm}^{3}$ (gives polymers $4 \mathrm{a}^{\prime \prime}-4 \mathrm{c}^{\prime \prime}$ ). The initial concentration of $t-\mathrm{BuO}^{-} \mathrm{K}^{+}$and the ligand was equal 


\section{Kind of of unsaturated starting groups for macromolecules initiated in presence of various ligands and monomer concentration}

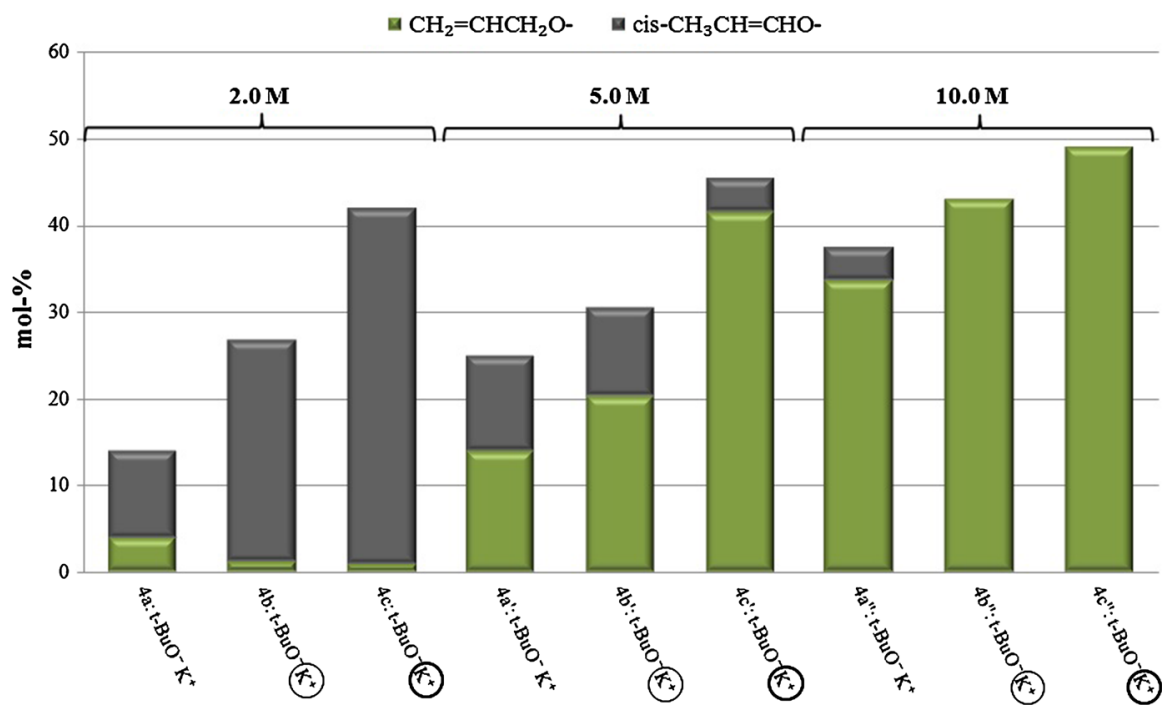

Fig. 4 Unsaturation of PPOs obtained in the polymerization initiated with $t$ - $\mathrm{BuO}^{-} \mathrm{K}^{+}$including the presence of ligands at different initial monomer concentration (light circled for 18C6, dark circled for C222)

to $0.1 \mathrm{~mol} / \mathrm{dm}^{3}$. The contents of unsaturated starting groups were estimated in $\mathrm{mol} \%$ of all starting groups based on ${ }^{13} \mathrm{C}$ NMR spectra by signals intensities of appropriate carbon atoms. Additionally, the chemical structure of unsaturated units was characterized. Figure 4 presents both the amounts and kind of unsaturated starting groups. The prepared polymers were characterized by broad range of unsaturation from 14.0 to $49.1 \mathrm{~mol} \%$. PPO obtained in the presence of uncomplexed $t$-BuO $\mathrm{K}^{+}$ (4a) exhibited the lowest unsaturation level compare to polymer $4 \mathrm{c}$ prepared using $t$ $\mathrm{BuO}^{-} \mathrm{K}^{+}$activated $\mathrm{C} 222$ at the same initial monomer concentration.

Unsaturation level and unsaturated groups structure can be discussed from three points of view:

1. effect of initial monomer concentration,

2. influence of ligand presence,

3. kind of ligand used.

Together with the increase of initial monomer concentration, distinct increase of polymer unsaturation was observed. As can be seen from Fig. 4 the investigated PPOs unsaturation strongly depends also on the presence and kind of macrocyclic ligands. In the polymerization performed with 18C6 and (4b) an increase of unsaturation as well as isomerization was observed. This effect was much more distinct when $\mathrm{C} 222$, a stronger ligand for $\mathrm{K}^{+}$, was applied for activation of the initiator. In this case (4c) $42 \%$ macromolecules have unsaturated starting groups, 
mainly cis-propenyloxy. Evidently, in the presence of the ligands the acceleration of monomer deprotonation (which depends on basicity of anions) occurs simultaneously with the acceleration of monomer ring opening (which depends on nucleophilicity of anions). However, the acceleration of the first reaction is greater than the acceleration of the second one. Isomerization of allyloxy groups depends on basicity of anions because it is ionic reaction. The highest isomerization in the system containing C222 can be explained by the highest basicity of chain growing centre.

Very high isomerization is probably connected with the presence of high amount of polar solvent, i.e. tetrahydrofuran in the system. Similar effect was previously observed for isomerization of simple allyl ethers in polar ether solvents as 1,2dimethoxyethane or dimethylsulfoxide [29]. The effect of the ligand on isomerization was also found at higher initial concentration of the monomer $\left(4 a^{\prime}-4 c^{\prime}\right)$. Isomerization diminishes markedly and allyloxy groups even prevail in the systems containing 18C6 or C222 in this case. It presumably results from decrease of polar solvent concentration in the system. At the highest initial monomer concentration isomerization is strongly limited and does not occur in the systems containing the ligands $\left(4 \mathrm{a}^{\prime \prime}-4 \mathrm{c}^{\prime \prime}\right)$.

Average molar mass and dispersity of synthesized polymers were determined by SEC using poly(propylene glycol) standards and the results are collected in Fig. 5. Values of $M_{n}$ correlate very well with unsaturation for three series of polymers presented in Fig. 4. Molar masses of polymers diminish simultaneously with increase of their unsaturation, because during the polymerization chain transfer to monomer and $t$ - $\mathrm{BuOH}$ formed in the initiation step take place.

The dispersities of the polymers are very low. Values of $M_{\mathrm{w}} / M_{\mathrm{n}}$ are in the range of 1.03-1.09, which indicates that cation exchange between terminated and active chain ends occurs with high rate (Scheme 6).

The results obtained in the present work indicate, that the effect of ligand on unsaturation and molar mass of PPOs prepared with $t$-BuO $\mathrm{K}^{+}$in the absence of alcohol is opposite to similar systems, in which potassium alkoxide/alcohol mixture was used for initiation [8, 22]. The presence of the ligand should accelerate propagation as well as deprotonation of monomer and alcohol. Presumably, in this case the acceleration of chain transfer to alcohol is greater than the acceleration of chain transfer to monomer, resulting in decrease of polymer unsaturation.

Based on ${ }^{13} \mathrm{C}$ NMR data for polymer $4 \mathrm{~b}$ the formation of four kinds of macromolecules, i.e. A, B, C and $\mathbf{D}$, which contain different terminal groups, was proposed (Scheme 7).

However, analysis of polymer $4 \mathrm{~b}$ by MALDI-TOF technique allow to detect two additional kinds of macromolecules, i.e. $\mathbf{E}$ and $\mathbf{F}$.

\section{Mechanistic aspects of initiation of PO polymerization}

It was stated in this work, that initiation of PO polymerization with potassium salts activated macrocyclic ligand occurs not only by ring-opening but also by deprotonation of monomer. Thus, initiators used behave as nucleophilic bases. Reacting as nucleophiles they open oxirane ring exclusively in the $\beta$-position with 


\section{$M_{n}$ and dispersity $\left({ }^{*}\right)$ of PPO obtained with various ligand systems and monomer concentration}

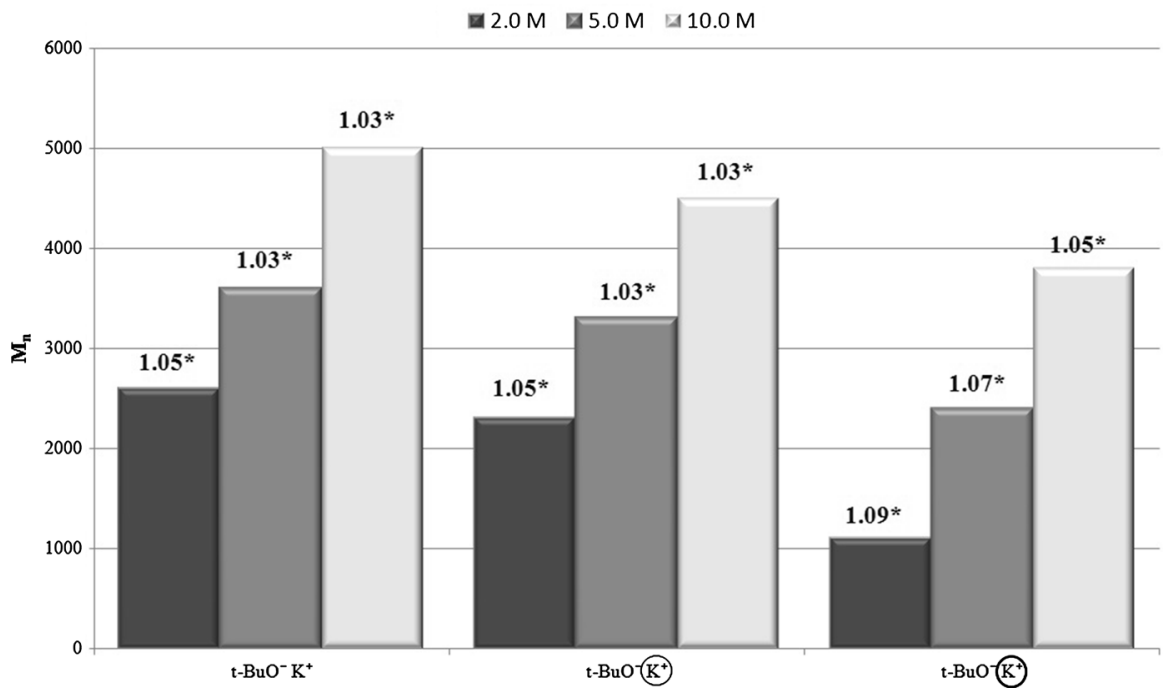

Fig. 5 Molar masses and dispersities of PPOs obtained in the polymerization initiated with $t$-BuO $\mathrm{Bu}^{+}$ including the presence of ligands at different initial monomer concentration (light circled for 18C6, dark circled for $\mathrm{C} 222$ )

$$
\ldots-\mathrm{O}^{-} \mathrm{K}^{+}+\ldots-\mathrm{OH} \rightleftharpoons \ldots-\mathrm{OH}+\ldots-\mathrm{O}^{-} \mathrm{K}^{+}
$$

Scheme 6 Cation exchange reaction involving polymer chains<smiles>[3H][Ba]COCC(C)OC</smiles>

A<smiles></smiles>

C<smiles>C=CCOCOCC(C)O</smiles>

$\mathbf{E}$<smiles>CC(O)COCCOCBr</smiles>

B<smiles>C/C=C\OCOCC(C)OC</smiles>

D<smiles>C/C=C\OCC(C)O</smiles>

Scheme 7 A schematic representation of PPO macromolecules formed in the polymerization initiated $t$ $\mathrm{BuO}^{-} \mathrm{K}^{+}$ 
one exception, when ring-opening occurs in the $\beta$ - as well as $\alpha$-position. Figure 6 a shows, for example, part of ${ }^{13} \mathrm{C}$ NMR spectrum of PPO obtained in the presence of $t$ - $\mathrm{BuO}^{-} \mathrm{K}^{+}$. The saturated starting $t$-butoxy groups give the signals at $66.52 \mathrm{ppm}$ $\left[\left(\mathrm{CH}_{3}\right)_{3} \underline{\mathrm{CO}}-\right]$ and $27.30 \mathrm{ppm}\left[\left(\mathrm{CH}_{3}\right)_{3} \mathrm{CO}-\right]$, respectively. In this case oxirane ring opens exclusively in the $\beta$-position.

Part of ${ }^{13} \mathrm{C}$ NMR spectrum of the polymer obtained in the polymerization with $i$-PrO $\mathrm{K}^{-}$is shown in Fig. 6b. In the region for the methyl signal of $i$-propoxy starting group $\left(\mathrm{CH}_{3}\right)_{2} \mathrm{CHO}-$ quite unexpectedly, two kinds of $i$-propoxy groups were detected at 22.01 and $22.15 \mathrm{ppm}$. We assumed, that these two signals could come from two different chain beginnings, formed during initiation by potassium $i$-PrO ${ }^{-}$, i.e. $\mathrm{R}_{1}$, $\left(\mathrm{CH}_{3}\right)_{2} \mathrm{CHO}-\mathrm{CH}_{2}-\mathrm{CH}\left(\mathrm{CH}_{3}\right) \mathrm{O}-(22.01$ and $72.09 \mathrm{ppm}$, respectively) and $\mathrm{R}_{2},\left(\mathrm{CH}_{3}\right)_{2} \underline{\mathrm{CHO}}-\mathrm{CH}\left(\mathrm{CH}_{3}\right)-\mathrm{CH}_{2} \mathrm{O}-(22.15$ and $72.13 \mathrm{ppm}$, respectively). The nucleophilic attack of initiator would concern less substituted carbon. Recently, we observed similar phenomenon in the polymerisation of styrene oxide in the presence of the same alkoxide [30]. In both systems two signals of $\left(\mathrm{CH}_{3}\right)_{2} \mathrm{CHO}-$ group were shown in the spectrum. The signals come from two different chain beginnings formed during initiation. However, in the polymerisation of 1,1dimethyloxirane (isobutylene oxide) only one signal of $\left(\mathrm{CH}_{3}\right)_{2} \mathrm{CHO}-$ group was detected (at 22, $21 \mathrm{ppm}$ ), which indicates ring-opening exclusively in the beta position. Hence one may conclude that steric reasons are responsible for the observed effect.

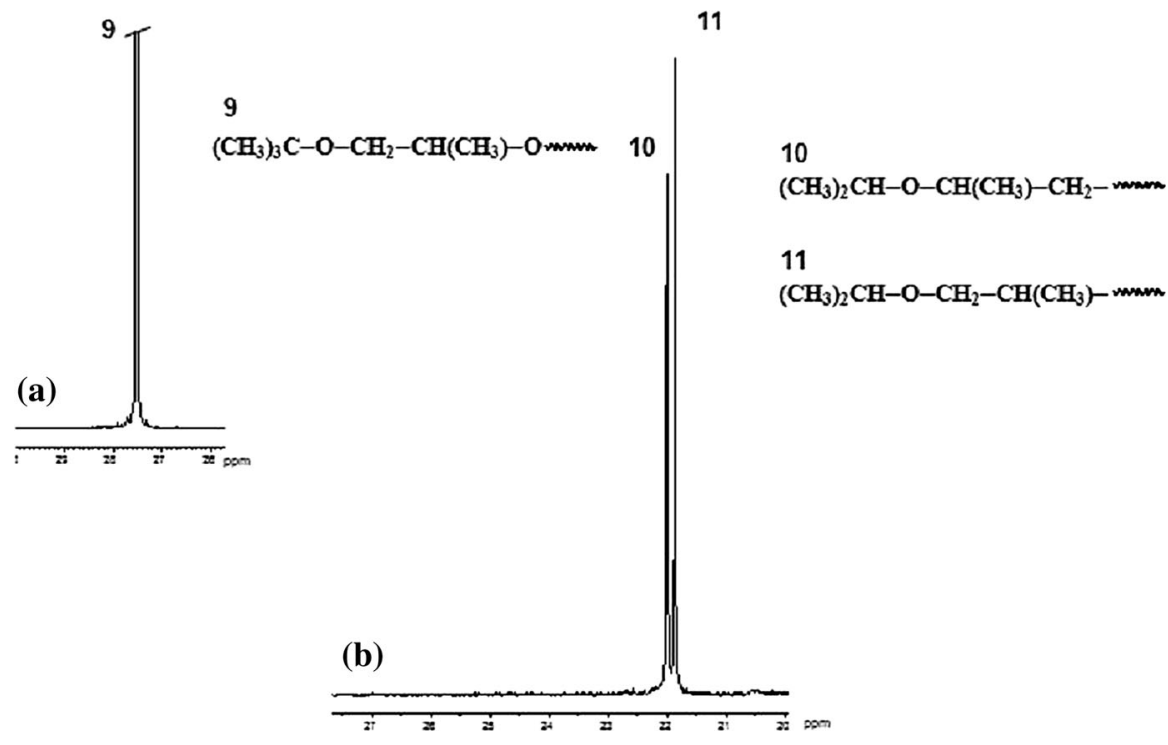

Fig. $6{ }^{13} \mathrm{C}$ NMR spectrum of PPO obtained in the presence of $t$ - $\mathrm{BuO}^{-} \mathrm{K}^{+}(\mathbf{a})$ and $i$-PrO $\mathrm{K}^{-}(\mathbf{b})$ 
It may be, therefore proposed, that during the initiation of polymerization with this salt the oxirane ring opens not only in the $\beta$-position, as it was observed usually in anionic polymerization of PO in the presence of other initiators, but also in the $\alpha$ position $(\beta / \alpha=53 \mathrm{~mol} \% / 47 \mathrm{~mol} \%$ ) (Scheme 8 ). Two signals of $i$-propoxy groups were also detected in ${ }^{13} \mathrm{C}$ NMR spectra of polymers obtained with other initiators, i.e. $\mathrm{K}^{+} \mathrm{H}^{-}$and $\mathrm{K}^{+} \mathrm{K}^{-}$. The course of the polymerizations initiated with $\mathrm{H}^{-}$and $\mathrm{K}^{-}$ anions was discussed in [31] and [32], respectively. Among several potassium salts $\mathrm{Ph}_{4} \mathrm{~B}^{-} \mathrm{K}^{-}$appeared to be completely inactive in PO polymerization. However, $\mathrm{Ph}_{3} \mathrm{HB}^{-} \mathrm{K}^{-}$easily initiated the process.

Again, signals of two kinds of $i$-propoxy groups were observed in the ${ }^{13} \mathrm{C} \mathrm{NMR}$ spectrum of the polymer. We explain this phenomenon by additional reaction which occurs immediately after initiation resulting in the formation of $i$ - $\mathrm{PrO}^{-} \mathrm{K}^{+}$ (Scheme 9).

Analysis of polymer by use of MALDI-TOF technique confirmed this assumption. Fragment of the spectrum from $\mathrm{m} / \mathrm{z}, 1000$ to 2000 was shown in Fig. 7.

Three series of peaks with peak-to-peak increment equal to the molar mass of the monomer $(58.08 \mathrm{~g} / \mathrm{mol})$ are shown in the spectrum. The series from $\mathrm{m} / \mathrm{z} 1012.0$ to 1942.2 represents macromolecules with $\mathrm{Ph}_{3} \mathrm{HB}-$ starting groups and $-\mathrm{CH}_{3}$ end groups. For example, the peaks at $\mathrm{m} / \mathrm{z}$ 1070.5, 1534.2 and 1884.0 (marked with stars) represents such macromolecules possessing 14, 22 and 28 monomer units $\left(M_{\text {calc }}=1071.2,1535.9\right.$ and 1884.3 , respectively $)$. The second series from $\mathrm{m} / \mathrm{z} 1026.2$ to 1956.2 represents macromolecules having $\left(\mathrm{CH}_{3}\right)_{2} \mathrm{CHO}-$ starting groups and $-\mathrm{OH}$ end groups as adducts with potassium ion. For example, the peaks at $\mathrm{m} / \mathrm{z}$ 1374.7, 1666.0 and 1898.0 (marked with triangles) represents such

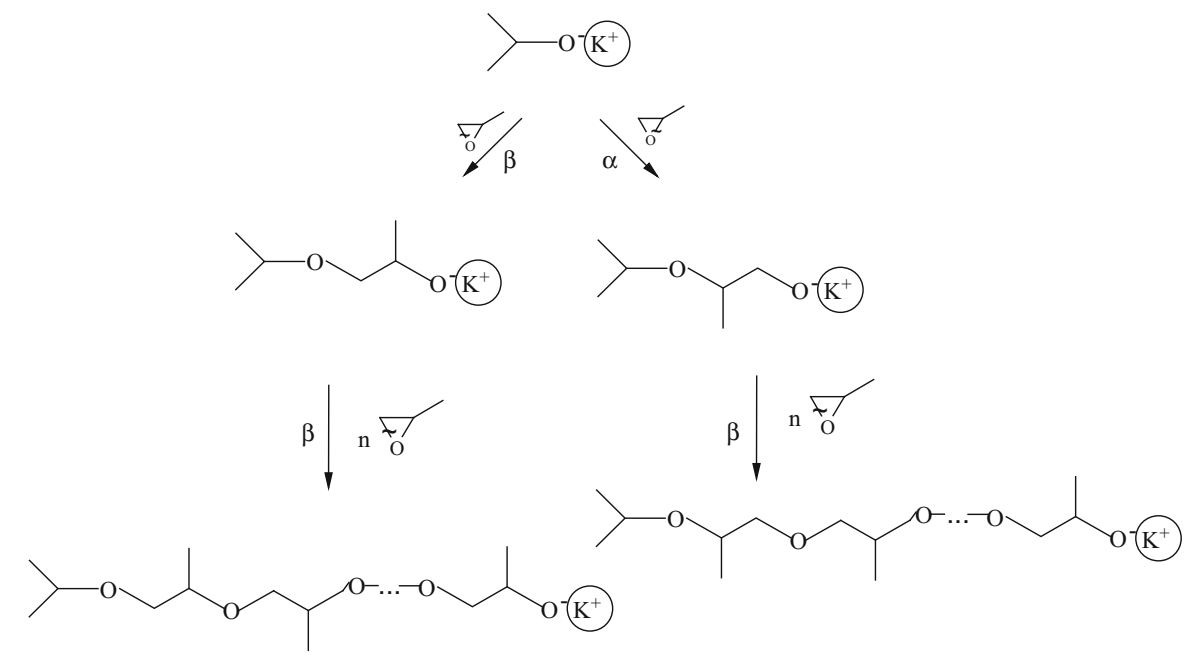

Scheme 8 Mechanism of initiation and propagation in PO polymerization initiated with $i-\mathrm{PrO}^{-} \mathrm{K}^{+}$ 


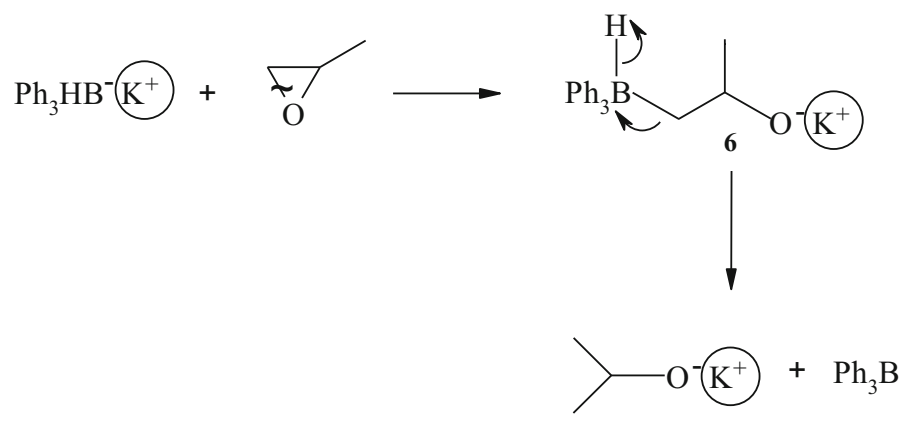

Scheme 9 Initiation of $\mathrm{PO}$ polymerization with $\mathrm{Ph}_{3} \mathrm{HB}^{-} \mathrm{K}^{+}$

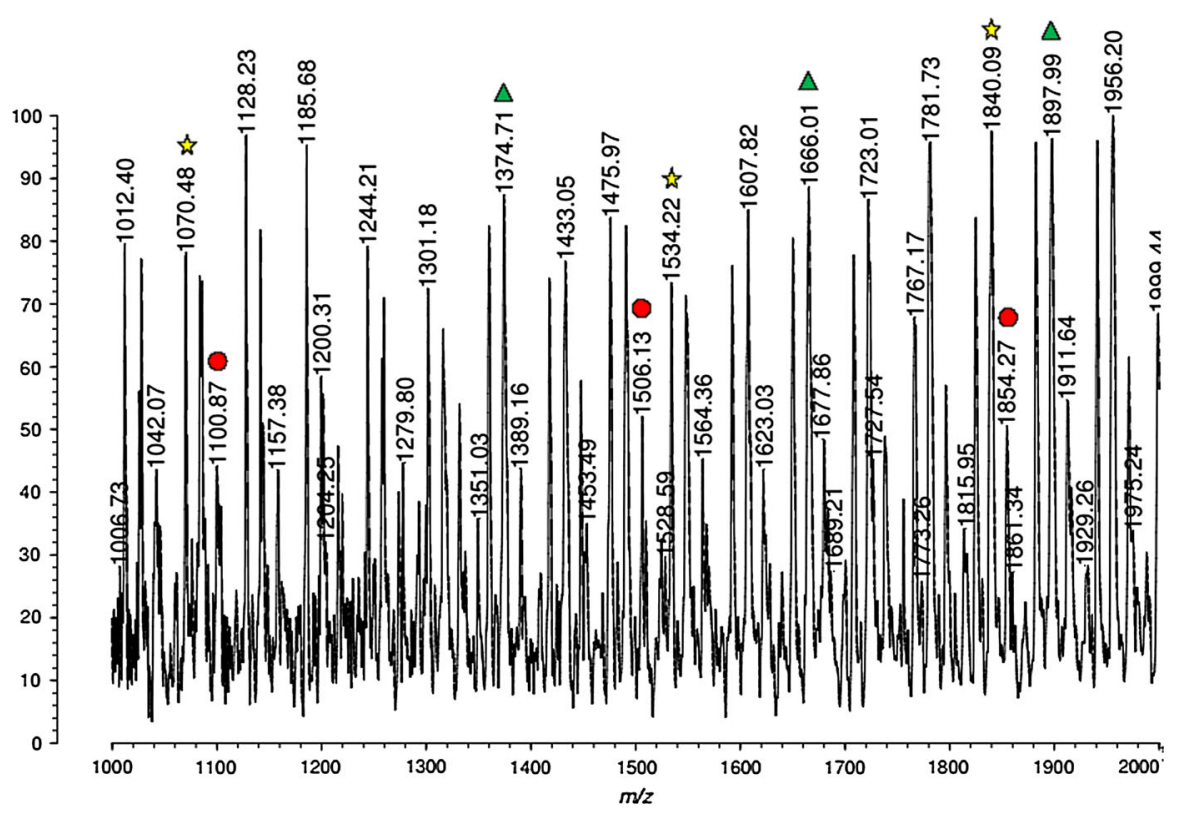

Fig. 7 MALDI-TOF spectrum of PPO obtained in the presence of $\mathrm{Ph}_{3} \mathrm{HB}^{-} \mathrm{K}^{+}$

macromolecules having 22,27 and 31 monomer units $\left(M_{\text {calc }}=1376.9,1667.3\right.$ and 1899.7, respectively). The third series from $\mathrm{m} / \mathrm{z} 1042.1$ to 1911.6 represents macromolecules with $\left(\mathrm{CH}_{3}\right)_{2} \mathrm{CHO}$ - starting groups and $-\mathrm{CH}_{3}$ end groups as adducts with potassium ion. For example, the peaks at $m / z 1100.9,1506.1$ and 1854.3 (marked with circles) represents such macromolecules possessing 17, 24 and 30 monomer units $M_{\text {calc }}=1100.5,1507.1$ and 1855.6, respectively).

Potassium salts activated macrocyclic ligand used for initiation behave also as bases. They deprotonate the monomer giving potassium allyloxide. However, in the presence of ligand this reaction cannot occur by E2 elimination (Scheme 1) due to steric hindrance and electronic reasons. Therefore, we proposed that direct 
deprotonation of the monomer takes place in this case. Such reaction is mediated not only by initiator but also with active centre of growing chain (Scheme 10).

Organopotassium intermediate, i.e. glycidylpotassium 7 formed after deprotonation of monomer is extremely unstable and decomposes immediately by oxirane ring-opening in the $\alpha$-position giving $\mathbf{3}^{\prime}$.

Further investigations suggested that some initiators, i.e. 5, 7, 10 and 11 deprotonates not only monomer but also the ligand. To identify the nonvolatile products of such reaction, methyl iodide was added to THF solution of initiator 10 . In GC-MS chromatogram of a sample separated from precipitated potassium iodide, the main product of the reaction was identified as pentaethylene glycol methyl vinyl ether, i.e. methyl derivative of potassium pentaethylene glycoxide vinyl ether, in $82 \%$ yield. After evaporation of the solvent, in the ${ }^{13} \mathrm{C}$ NMR spectrum of the sample, aside from the carbon signals of $-\mathrm{CH}_{2} \mathrm{O}-$ groups in the range of 67.0-72.0 ppm, a signal at $59.0 \mathrm{ppm}$ arising from $\mathrm{CH}_{3} \mathrm{O}-$ group and the signals due to the vinyl function at 86.9 and $151.3 \mathrm{ppm}$ were found. These observation confirmed the result of analysis by GC-MS method. Basing on these results we proposed the mechanism of the reaction of initiator with $18 \mathrm{C} 6$ being in the complex with counterion (Scheme 11).

Potassium alkoxide $\mathbf{8}$ formed in this reaction became effective initiator of the polymerization mediated with salts $5,7,10$ and 11 . It was responsible for the presence of the signals of vinyloxy starting groups and $-\mathrm{CH}_{2} \mathrm{O}-$ groups in ${ }^{13} \mathrm{C} N M R$ of some polymers. Participation of $\mathbf{8}$ in initiation of polymerization confirms analysis by MALDI-TOF technique. The exemplary spectrum of polymer 10 was is in Fig. 8. Three series of peaks with peak-to-peak increment equal to the molar mass of the monomer $(58.08 \mathrm{~g} / \mathrm{mol})$ are shown in the spectrum. The main series from $\mathrm{m} / \mathrm{z} 539.9$ to 1942.5 represents macromolecules with allyloxy, cis- and transpropenyloxy starting groups and $-\mathrm{CH}_{3}$ end groups. For example, the peaks at $m / z, 712.9,1118.2$ and 1637.7 represents such macromolecules having 12, 19 and 28 monomer units $\left(M_{\text {calc }}=711.0,1117.5\right.$ and 1640.2 , respectively). The second main series from $\mathrm{m} / \mathrm{z} 525.9$ to 1972.4 represents macromolecules possessing $\left[\left(\mathrm{CH}_{3}\right)_{3}\right.$ $\mathrm{Si}]_{2} \mathrm{~N}-$ starting groups and $-\mathrm{CH}_{3}$ end groups. For example, the peaks at $\mathrm{m} / \mathrm{z}, 756.9$, 1277.5 and 1797.8 represents such macromolecules having 10, 19 and 28 monomer units $\left(M_{\text {calc }}=756.2,1278.9\right.$ and 1801.6, respectively). The third series from

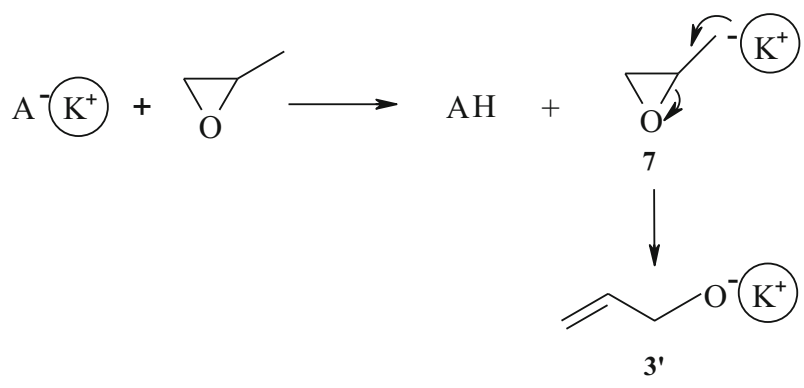

Scheme 10 Direct deprotonation of PO in the polymerization with potassium salt activated macrocyclic ligand, where $\mathrm{A}^{-}$denotes anion of initiator or growing chain end 


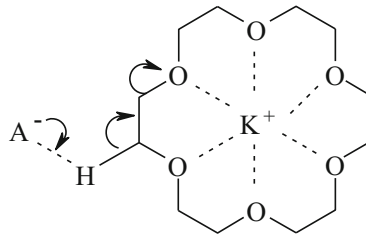<smiles>C=COCCOCCOCCOCCOCCOCCOCCOCCOCCOCCOC</smiles>

Scheme 11 Decomposition of 18C6 by initiator

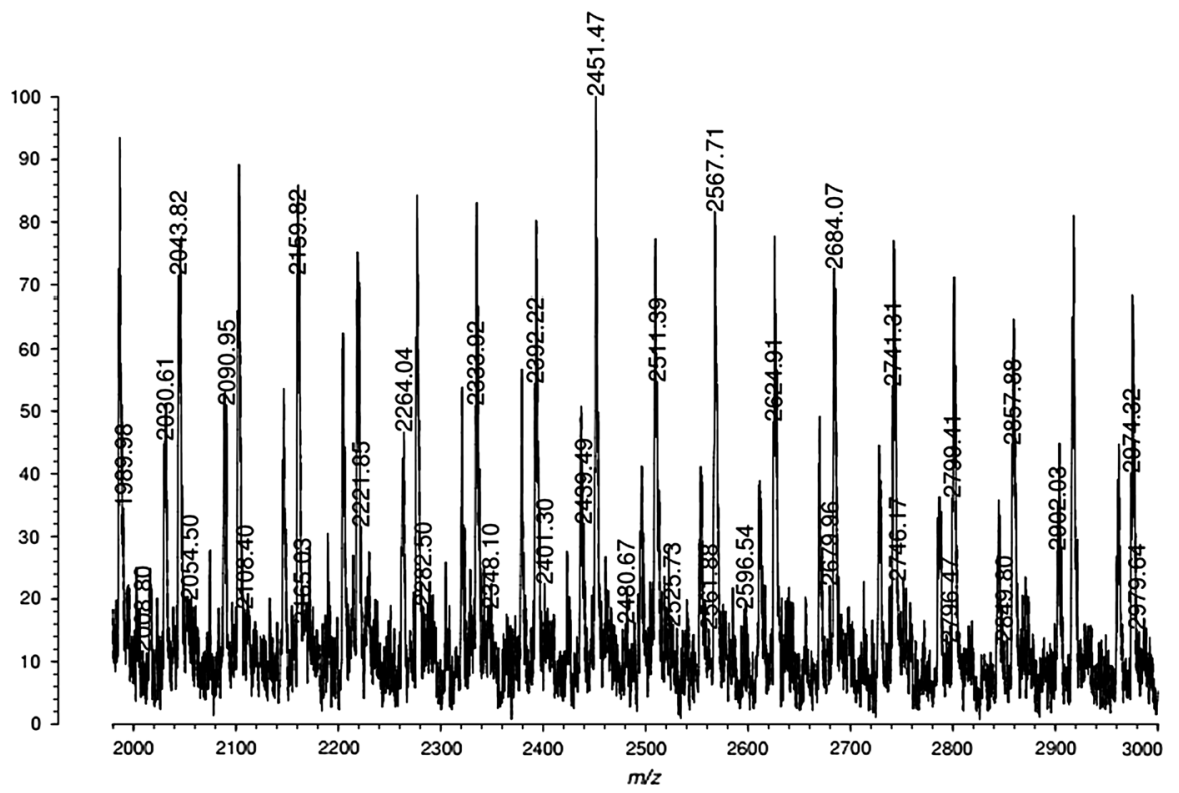

Fig. 8 MALDI-TOF spectrum of PPO obtained in the presence of $\left[\left(\mathrm{CH}_{3}\right)_{3} \mathrm{Si}_{2} \mathrm{~N}^{-} \mathrm{K}^{+}\right.$

$m / z 511.9$ to 1900.1 represents macromolecules with $\mathrm{CH}_{2}=\mathrm{CHO}\left(\mathrm{CH}_{2} \mathrm{CH}_{2} \mathrm{O}\right)_{5}-$ starting groups and $-\mathrm{CH}_{3}$ end groups. For example, the peaks at $\mathrm{m} / \mathrm{z} 511.9,858.0$ and 1380.0 represents such macromolecules with 6, 10 and 19 monomer units $\left(M_{\text {calc }}=510.4,858.8\right.$ and 1381.5 , respectively $)$. Similar phenomenon was observed till now in PO polymerization initiated $\mathrm{K}^{+}\left(15\right.$-crown-5) ${ }_{2} \mathrm{~K}^{-}$[32]. In this system organopotassium salt formed as intermediate causes decomposition of macrocyclic agent. Thus, one should take into account the possibility of ligand decomposition, when propylene oxide polymerization was carried out in the presence of alkali metal salts. 


\section{Conclusions}

- Unsaturation of PPOs prepared in the presence of different potassium salts activated 18C6 is high and depends strongly on the kind of initiator, changing from $10.1 \%$ for potassium triphenylmethane to $86.6 \%$ for potassium hydroxide.

- The source of unsaturation (starting allyloxy group) is direct deprotonation of the monomer with initiator and active chain end; unexpectedly, in some systems additional kind of unsaturation (vinyloxy groups) was found, which results from deprotonation of $18 \mathrm{C} 6$ with initiator.

- Unsaturation of PPOs synthesized with selected initiator, i.e. potassium $t$-butoxide increases markedly after its activation with 18C6 and especially C222; this effect is opposite to that observed earlier in the polymerization initiated with alkoxide/alcohol mixtures after addition of complexing agent.

- Isomerization of allyloxy groups to cis-propenyloxy ones depends on the kind of initiator, ligand and initial monomer concentration; the highest isomerization was observed in the polymerization initiated with potassium alkoxides and low initial monomer concentration.

- During the initiation of the polymerization oxirane ring of PO opens exclusively in the $\beta$-position, except the systems containing potassium $i$-propoxide; in this case ring-opening occurs unexpectedly in the $\beta$ - and $\alpha$-position $(\sim 1 / 1)$.

\section{Compliance with ethical standards}

Conflict of interest The authors declare that they have no conflict of interest.

Open Access This article is distributed under the terms of the Creative Commons Attribution 4.0 International License (http://creativecommons.org/licenses/by/4.0/), which permits unrestricted use, distribution, and reproduction in any medium, provided you give appropriate credit to the original author(s) and the source, provide a link to the Creative Commons license, and indicate if changes were made.

\section{References}

1. Gosa KI, Uricanu V (2002) Emulsions stabilized with PEO-PPO-PEO block copolymers and silica. Colloids Surf A 197:257-269. doi:10.1016/S0927-7757(01)00902-5

2. Herzberger J, Niederer K, Pohlit H, Seiwert J, Worm M, Wurm FR, Frey Holger (2016) Polymerization of ethylene oxide, propylene oxide, and other alkylene oxides: synthesis, novel polymer architectures, and bioconjugation. Chem Rev 116:2170-2243. doi:10.1021/acs.chemrev.5b00441

3. de Lucas A, Rodriguez I, Perez-Collado M, Sanchez P (2002) Production of polyether polyols using caesium as catalyst. Polym Int 51:1041-1046. doi:10.1002/pi.907

4. Mathur AM, Drescher B, Scranton AB, Klier J (1998) Polymeric emulsifiers based on reversible formation of hydrophobic units. Nature 392:367-370. doi:10.1038/32856

5. Jeong B, Bae YH, Lee DS, Kim SW (1997) Biodegradable block copolymers as injectable drugdelivery systems. Nature 388:860-862. doi:10.1038/42218

6. Brocas AL, Mantzaridis Ch, Tunc D, Carlotti S (2013) Polyether synthesis: from activated or metalfree anionic ring-opening polymerization of epoxides to functionalization. Prog Polym Sci 38(6):845-873. doi:10.1016/j.progpolymsci.2012.09.007 
7. Cendejas G, Flores-Sandoval AC, Huitrón N, Herrera R, Zamudio-Rivera LS, Beltrán HI, Vázquez F (2008) Theoretical and experimental studies of the initiator influence on the anionic ring opening polymerization of propylene oxide. J Mol Str 879:40-52. doi:10.1016/j.molstruc.2007.08.023

8. Ionescu M (2005) Chemistry and technology of polyols for polyurethanes. Rapra Technology Limited, Shawbury, Shrewsbury, Shropshire, UK. ISBN: 978-1-84735-035-0

9. Chattopadhyay D, Raju K (2007) Structural engineering of polyurethane coatings for high performance applications. Prog Polym Sci 32:352-418

10. Becker H, Wagner G (1984) Zur Übertragungsreaktion bei der anionichen Polymerisation von Oxiranen VI. Zum Einfluß von Kronenetherzusätzen auf die Polymerisation von Propylenoxid. Acta Polym 35:28-32. doi:10.1002/actp.1984.010350106

11. Simons DM, Verbanc JJ (1960) The polymerization of propylene oxide. J Polym Sci 44:303-311. doi:10.1002/pol.1960.1204414403

12. Yu GE, Heatley F, Booth C, Blease TG (1994) Anionic polymerization of propylene oxide: isomerization of allyl ether to propenyl ether end groups. J Polym Sci Part A Polym Chem 32:1131-1135. doi:10.1002/pola.1994.080320615

13. Freidly HR (1992) In: Gum WF, Riese W, Ulrich H (eds) Reaction polymers. Hanser Oxford University Press, New York, USA, pp 66-91. ISBN: 9780195209334

14. Furukawa J, Saegusa T (1963) Polymerization of aldehydes and oxides. Interscience Publishers, New York, p 125

15. Yu GE, Masters AJ, Heatley F, Booth C, Blease TG (1994) Anionic polymerisation of propylene oxide. Investigation of double-bond and head-to-head content by NMR spectroscopy. Macromol Chem Phys 195:1517-1538. doi:10.1002/macp.1994.021950506

16. Becker H, Wagner G, Stolarzewicz A (1982) Zur Übertragungsreaktion bei der anionischen Polymerisation von Oxiranen. III. Zur Dynamik der Doppelbindungsbildung bei der Propylenoxidpolymerisation. Acta Polym 33:34-37. doi:10.1002/actp.1982.010330107

17. Gladkovski GA, Golovina LP, Vedeneeva GF, Lebedev VS (1973) Vysokomol Soed A15:1221-1228

18. Stolarzewicz A, Becker H, Wagner G (1981) Zur Übertragungsreaktion bei der anionischen Polymerisation von Oxiranen. I. Zum Einfluß des Initiatorsystems auf die Kettenübertragung. Acta Polym 32:483-486. doi:10.1002/actp.1981.010320811

19. Becker H (1981) Wagner G and Stolarzewicz A (1981), Zur Übertragungsreaktion bei der anionischen Polymerisation von Oxiranen. II. Zur Kettenübertragung bei der Copolymerisation von Propylen- und Ethylenoxid. Acta Polym 32:764-766. doi:10.1002/actp.1981.010321207

20. Penczek S, Cypryk M, Duda A, Kubisa P, Słomkowski S (2007) Living ring-opening polymerizations of heterocyclic monomers. Prog Polym Sci 32:247-282. doi:10.1016/j.progpolymsci.2007.01.002

21. Ionescu M, Mihalache I, Dumitru V, Stoenescu F, Ion V (1988) Revista de Chimie. Bucuresti 39:1060-1067

22. Ding J, Heatley F, Price C, Booth C (1991) Use of crown ether in the anionic polymerization of propylene oxide-2. Molecular weight and molecular weight distribution. Eur Polym J 27:895-899. doi:10.1016/0014-3057(91)90029-N

23. Grobelny Z, Matlengiewicz M, Jurek J, Michalak M, Kwapulińska D, Swinarew A, Schab-Balcerzak E (2013) The influence of macrocyclic ligands and water on propylene oxide polymerization initiated with anhydrous potassium hydroxide in tetrahydrofuran. Eur Polym J 49:3277-3288. doi:10.1016/j. eurpolymj.2013.06.035

24. Brown CA (1974) Potassium hydride, highly active new hydride reagent. Reactivity, applications, and techniques in organic and organometallic reactions. J Org Chem 39:3913-3918. doi:10.1021/ jo00940a025

25. Buncel E, Menon B (1976) Metallation of weak hydrocarbon acids by potassium hydride-18-crown-6 polyether in tetrahydrofuran and the relative acidity of molecular hydrogen. J Chem Soc Chem Comm, pp 648-649. doi:10.1039/C39760000648

26. Jedliński Z, Stolarzewicz A, Grobelny Z (1986) Decomposition of 18-crown-6 solutions in tetrahydrofuran containing dissolved potassium. Macromol Chem Phys 187:795-799. doi:10.1002/ macp. 1986.021870410

27. Siggia S (1963) Quantitative organic analysis via functional groups. J. Wiley, New York, p 241

28. Kricheldorf HR, Scharnagl NJ (1989) Polyactones. 17. Anionic polymerization of $\beta$-D.L-butyrolactone. J Macromol Sci Part A Pure App Chem A26:951-968. doi:10.1080/00222338908052023

29. Price CC, Snyder WH (1961) Solvent effects in the base-catalyzed isomerization of allyl to propenyl ethers. J Am Chem Soc 83:1773. doi:10.1021/ja01468a062 
30. Grobelny Z, Matlengiewicz M, Jurek-Suliga J et al (2017) Ring opening polymerization of styrene oxide initiated with potassium alkoxides and hydroxyalkoxides activated by 18-crown-6: determination of mechanism and preparation of new polyether-polyols. Polym Bull, pp 1-18. doi:10.1007/ s00289-017-1976-4

31. Stolarzewicz A, Neugebauer D, Grobelny J, Grobelny Z (1998) Polymerization of oxiranes in the presence of potassium hydride. Polimery 43:443-448

32. Grobelny Z, Stolarzewicz A, Neugebauer D, Morejko-Buż B (2002) Structure of poly(propylene oxide) obtained in the presence of $\mathrm{K}^{-}, \mathrm{K}^{+}(15$-crown-5) 2 . Eur Polym J 38:1065-1070. doi:10.1016/ S0014-3057(01)00282-8 